\title{
Adaptive Reuse of Religious Heritage and Its Impact on House Prices
}

\author{
Caixia Liu ${ }^{1} \cdot{\text { Xiaolong } \text { Liu }^{2}}$
}

Accepted: 28 September 2020/Published online: 12 October 2020

(C) The Author(s) 2020

\begin{abstract}
Due to social demographic change and secularization, religious heritage sites in Europe are on the verge of losing their original functions. While the adaptive reuse seems to be a proactive strategy to preserve the historical and cultural value embedded in religious heritage sites, little is known concerning its external impact. This paper aims to fill this gap by investigating the external effect of reusing religious heritage on surrounding house prices. Employing both the parametric and non-parametric difference-indifferences hedonic model on a sample of 42 projects of reusing religious heritage and a rich dataset of housing transactions in the Netherlands, we find significant positive externality of reusing religious heritage on local house prices. The external effects are heterogeneous across differentiated project size and monumental status. Larger religious heritage reuse projects and those listed as national monuments exert greater influence on surrounding house prices.
\end{abstract}

Keywords Religious heritage $\cdot$ Adaptive reuse $\cdot$ Urban revitalization $\cdot$ House prices

JEL-Classification $\mathrm{C} 21 \cdot \mathrm{D} 62 \cdot \mathrm{D} 84 \cdot \mathrm{O} 22 \cdot \mathrm{R} 31$

\section{Introduction}

Religious heritage constitutes an important element that shapes the urban historical and cultural landscape in Western European countries. Over the last few decades, due to

Xiaolong Liu

xiaolong.liu@ rug.nl

Caixia Liu

cx0619.liu@gmail.com

1 College of Economics, Jinan University, Guangzhou 510632, China

2 Real Estate Center, Department of Economic Geography, Faculty of Spatial Sciences, University of Groningen, Groningen 9747AD, The Netherlands 
secularization and social demographic changes, more and more churches and monasteries have been underused or closed, losing their original functions of worship and hosting religious events. As a consequence, these underused or vacant religious sites are inevitably neglected or even demolished eventually in spite of the cultural and historical value embedded in them. Adaptive reuse of redundant historical buildings is increasingly recognized as being fundamental to sustainable urban development since it can contribute to the preservation of cultural and historical value in place, while, in the meantime, serve as an effective tool to stimulate local economic development (Latham 2016). Hence, the adaptive reuse brings about benefits not only to users and investors when redundant historical buildings are transformed with new functions while maintaining their original physical appearance, but also to the welfare of local communities in the form of amenity provision. For instance, reusing existing historical buildings is expected to create attractive inner-city environment that draws residents with high income and education to the city (Heath et al. 2013). Reused religious heritage, in particular, is valued as visible community amenity that contributes to the living environment and people's quality of life (Diamond and Tolley 2013). As house prices are partially determined by the willingness to pay by households for residential amenity (Small and Steimetz 2012), it seems plausible to argue that, besides cultural and historical value preservation, the adaptive reuse of redundant religious heritage may bring desirable amenities to nearby residents which can potentially be capitalized in surrounding property values.

In this paper, we empirically examine the external effect of reusing religious heritage on local house prices. It connects to the literature on the externalities imposed by historic preservation as well as urban revitalization. Previous research establishes predominant findings that historic preservation and urban revitalization projects bring about spillover to local housing market. For instance, positive external impact on house prices can be associated with historic designation (Coulson and Leichenko 2001; Ahlfeldt and Maennig 2010; Noonan and Krupka 2011), subsidized housing (Schwartz et al. 2006), brownfield redevelopment (De Sousa et al. 2009; Woo and Lee 2016, urban renewal (Lee et al. 2017; Liang et al. 2020), and redevelopment of industrial heritage sites (Van Duijn et al. 2016). With reference to the existing literature, little is known as to how reusing religious heritage affects the welfare of local communities in the form of housing price capitalization. Hence, the current paper aims to add to the policy evaluation of urban revitalization that contributes to the quality of existing housing stock.

As a place-based policy, adaptive reuse of religious heritage provides a quasiexperimental shock to the local housing market. In our research design, we begin with employing the standard parametric difference-in-differences hedonic approach to estimate the magnitude and significance of the average external effect of the adaptive reuse of religious heritage. We then use a non-parametric difference-in-differences method as proposed by Diamond and McQuade (2019) to transform house price level data to the derivative of house prices with respect to the distance from the religious heritage sites to examine the external effect of the adaptive reuse of religious heritage at any specific location within its proximity, and how the effect varies over space and time. For both the parametric and non-parametric estimation, we assign the treatment year being the year of project commencement to accommodate the potential anticipation effect that, given the lengthy process of project implementation, the external effect of the project is 
very much likely to be capitalized in local house prices before project completion. Such anticipation effect has also been well documented in the literature, for instance, Van Duijn et al. (2016) and Liang et al. (2020). We also pay attention to the heterogeneity of external effect among reuse projects with different scale and religious heritage sites designated with distinct monumental status.

Our general findings suggest that the adaptive reuse of religious heritage has a significantly positive external effect on surrounding property values with the average treatment effect being $2.17 \%$. However, the magnitude of the external effect varies depending on the scale of religious heritage reuse project as well as the monumental status of the religious heritage site. Both large-scale reuse projects and religious heritage sites listed as national monument exert greater impact on surrounding house prices. Specifically, our estimates in the parametric difference-in-differences setting show that the average treatment effects for projects with size being more than 5000 square meters and religious heritage sites listed as national monument are $3.38 \%$ and $2.28 \%$ respectively. Our estimates in the non-parametric difference-in-differences setting indicate spatial decay in terms of the magnitude of the external effect such that the effect becomes smaller as properties are located further away from the religious heritage site. Along the temporal dimension, the external effect of reusing religious heritage sites is larger for property transactions taking place later in time after the project commencement. With these results, this study provides important reference for stakeholders in the welfare evaluation of reusing religious heritage sites.

The remainder of this paper is structured as follows. Section 2 briefly reviews the literature. Section 3 provides the institutional background underlying this study. Section 4 presents the methodology and Section 5 describes the data used in the analysis. Empirical results are reported and discussed in Section 6. Section 7 concludes.

\section{Literature Review}

There is a large body of empirical research on the effects of policies relating to historic preservation. One stream of previous studies has concentrated on the public designation of historic buildings or districts and its impact on property values. Results are mixed across selection of sample and empirical approach. On the one hand, historic designation impedes property's optimal use, which could reduce the market value of regulated properties. Asabere et al. (1994) use hedonic framework to examine the effect of local historic preservation on house price in Philadelphia. They find that the value of designated apartments decreased by $24 \%$ as compared to those non-designated properties. Noonan and Krupka (2011) contend that most of previous studies fall victim to endogeneity problems. They employ an instrumental variable approach, and show negative effect on local house prices both within and outside historic districts. Heintzelman and Altieri (2013) adopt repeated sales analysis and document that the creation of historic district reduces local house prices between 11.6 and $15.5 \%$ in the Boston-Cambridge-Quincy MSA between 2000 and 2007. However, externalities of historic district on nearby house prices do not seem to be present.

Historic designation, on the other hand, is perceived as desirable amenity and contributes to the quality of neighborhood, which may be capitalized into the value of surrounding properties. Coulson and Leichenko (2001) use the standard hedonic 
model to estimate the external effects associated with historic designation in Abilene, Texas. The study reports that preservation activities generate significantly positive spillover to surrounding neighborhoods. Therefore, overall benefits more than outweigh costs associated with historical designation. Noonan (2007) takes a sample of Chicago home sales during the 1990s to examine the price effect of historic designation. Results suggest that landmark buildings bring about positive spillover effect on house prices. Ahlfeldt and Maennig (2010) arrive at a similar conclusion in their analysis of the influence of designated landmarks on condominium prices in Berlin, Germany, where their results indicate that designated landmarks exert positive spillover on surrounding property prices. Zahirovic-Herbert and Gibler (2014) argue that historic designation is capitalized through different mechanisms between within and outside the historic districts, namely, historic designation is capitalized in a price premium within the historic district while in a shorter market duration nearby.

In contrast to the passive historic preservation by means of public designation, adaptive reuse of under-used or abandoned historic buildings is increasingly seen as a sustainable and active strategy towards historic preservation as well as urban revitalization. Previous research attempts to explore externalities of urban revitalization projects across spatial and temporal dimensions. Using geocoded administrative data, Schwartz et al. (2006) estimate a difference-indifferences hedonic model to investigate the external effects of place-based subsidized housing in New York City. They find significant and sustained positive external effect on surrounding house prices. De Sousa et al. (2009) employ cross-sectional hedonic models to measure the impact of brownfield redevelopment on nearby residential property values in two U.S. cities. They find a net increase of nearby housing prices with $11.4 \%$ in Milwaukee and $2.7 \%$ in Minneapolis, but the project size and public funding amount have minor impacts on this effect. Similar findings are also reported by Woo and Lee (2016) that examine the external impact of brownfield redevelopment on housing prices in Ohio from 1996 to 2007. Van Duijn et al. (2016) use a difference-in-differences design to investigate the external effect of industrial heritage redevelopment on house prices in the Netherlands. They find that the negative external effect is associated with the period before the start of redevelopment and positive external effect is revealed after the project completion. Koster and Rouwendal (2017) study the economic effects of public investments in the renovation and maintenance of historic buildings, showing that 1 million euro per square kilometers increase in investment leads to $1.5-$ $3 \%$ increase in housing prices. Aarland et al. (2017) exploit quasi-experimental approach and the spatial error model to investigate the impact of area-based intervention programs in Norway with mixed results. Significant housing price appreciation is discovered in two areas, while, in other areas, the programs have no significant or even negative impact on house prices.

In view of the literature mentioned above, there have been particularly scarce empirical studies quantifying the external effect of reusing cultural heritage sites. Hence, the current paper aims at filling this research gap by contributing to the economic literature that investigates the role of historic preservation policies in the determination of welfare of local communities. 


\section{Background}

Religious heritage, such as churches and monasteries, are generally located in the heart of local communities that characterizes European urban landscape. They are not only sacred places for religious activities, but also symbols of cultural identity and social cohesion. Nevertheless, since 1960s, the postwar European countries have experienced a quick secularization with dramatically declining participation in religious practice (Halman and Draulans 2006; Ruiter and Van Tubergen 2009). The Netherlands presents itself as a classic example to demonstrate such a transition. Fig. 1 illustrates the trend of Dutch religious denomination between 1990 and 2015. It is clearly visible that the proportion of population that claims no religious affiliations grows rapidly. In 1990, about $38 \%$ of Dutch population did not have any religious denomination, while it surpassed $50 \%$ in 2015. In the meantime, the proportion of Dutch population with beliefs in Dutch Reformed or Roman Catholicism dropped dramatically.

Given declining religious participation over the past two decades in the Netherlands, some religious heritage sites are inevitably under-used or closed. Hence, reusing the redundant religious heritage seems to be a promising solution to protect the historic and cultural value of these buildings while maximizing their potential for other functions. It is broadly acknowledged that adaptive reuse is considered as an important strategy towards heritage conservation and urban livability. In the process of adaptive reuse, community authorities, property owners and regulators take the initiative to look for adaptive options of redeveloping such buildings (Velthuis and Spennemann 2007). Non-profit foundations also exist in support for the reuse of religious heritage. ${ }^{1}$ In the recent decades, a rising number of abandoned churches and monasteries have been converted into public facilities, commercial premises and residential buildings such as sports center, concert hall, library, restaurant, office and apartment. By means of adaptive reuse, religious heritage remains to be publicly accessible and attractive to local communities.

\section{Methodology}

Our identification strategy starts with the parametric difference-in-differences model that is widely used to evaluate the spillover effects of place-based policies in the existing literature (Schwartz et al. 2006; Ooi and Le 2013; Dröes and Koster 2016; $\mathrm{Wu}$ and Wang 2017). The model takes the following specification:

$$
\ln P_{i t}=\alpha+\text { streat }_{i t}+\beta \text { treat }_{i t} \times \text { post }_{i t}+\gamma X_{i t}+\varepsilon_{i t}
$$

where the dependent variable $\ln P_{i t}$ is the natural logarithm of the transaction price of house $i$ in year $t$. treat $_{i t}$ is a dummy variable which equals 1 if the house is located in the treatment area and 0 otherwise with $\rho$ as its coefficint. post $t_{i t}$ is a dummy variable that takes the value of 1 if the year of housing transaction is not earlier than the treatment

\footnotetext{
${ }^{1}$ Examples for non-profit organizations: Future for Religious Heritage (Brussels), Het Restauratiefonds (Amersfoort), Cultural Heritage Agency (Amersfoort), Stiching Oude Hollandse Kerken (Amsterdam), Stichting Oude Groninger Kerken (Groningen), Stichting Oude Zeeuwse Kerken (Middelburg).
} 


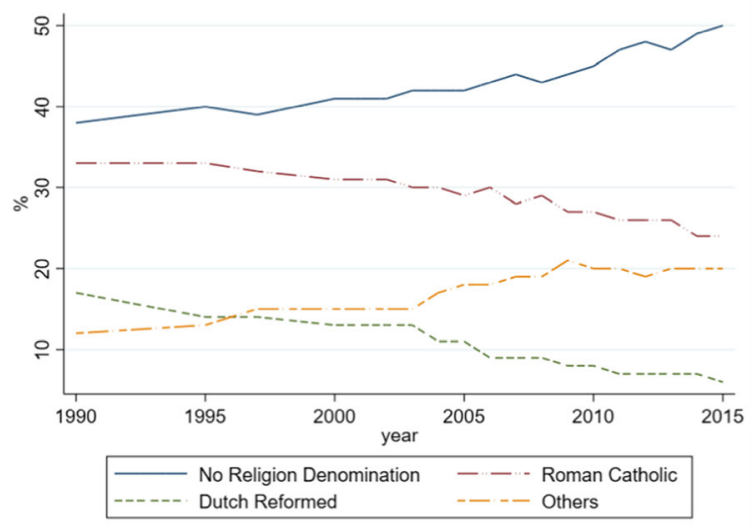

Fig. 1 Dutch population (aged 18 years and above) by religious denomination. Source: Statistics Netherlands (CBS)

year and 0 otherwise. treat $_{i t} \times$ post $_{i t}$ is the interaction of treat $i t$ and post $_{i t}$, and $\beta$ is the coefficint that captures the average treatment effect of religious heritage reuse. $X_{i t}$ is a vector with dimension $k \times 1$ that includes housing characteristics such as floor size, number of rooms, housing type, building year and neighborhood characteristics such as demographic structure, population density, average household size, etc. $\gamma$ is a vector of dimension $1 \times k$ that contains corresponding coefficients for variables in $X_{i t}$. $\varepsilon_{i t}$ is the error term.

We define the treatment area by drawing an inner ring around the religious heritage site with a radius of $1 \mathrm{~km}$, and outside the treatment area and up to an outer ring with a radius of $2 \mathrm{~km}$ is considered as the control area. Hence, properties located within $1 \mathrm{~km}$ distance from the nearest religious heritage site are classified into the treatment group, and control group consists of properties located between 1 and $2 \mathrm{~km}$ away from the nearest religious heritage site. Additionally, we take the treatment year as the year of project commencement rather than the year when the reuse project is accomplished and put into service. We adopt such definition to capture the potential anticipation effect that seems most likely for projects extending for multiple years (Van Duijn et al. 2016; Liang et al. 2020).

The parametric approach mentioned above delivers the average treatment effect, however, it can be argued that the treatment effect might not be constant along spatial and temporal dimensions. For instance, houses that are within the close proximity to the reuse projects may enjoy higher price premium than those located further away. Similarly, the extent to which the externality of reuse projects is capitalized may be different between houses that are sold right after the start of the projects and those transacted after the project completion. To accommodate the heterogeneity in terms of the treatment effect, we adopt a non-parametric spatial difference-in-differences method first developed by Diamond and McQuade (2019). By comparing housing price trends close to the religious site with their counterparts sligthly further away before and after religious heritage reuse, this methodology allows us to capture external effects of religious heritage reuse and how they vary with distance from the religious site and time since the commencement of reuse projects. Thus, this would yield a more detailed picture of the variation of the treatment effect across space and time. 
To estimate the spatial non-parametric difference-in-differences model, we index all religious heritage sites by a unique area $l$ which extends with a $2-\mathrm{km}$ radius circling around the religious heritage site, and each house $i$ has its polar coordinates $\left(r_{i}, \theta_{i}\right)$ relative to the religious heritage site in area $l$. The function of house prices in area $l$ is given by:

$$
\ln P_{i t}=\widetilde{D}\left(r_{i}, \tau_{i}\right)+\omega_{l}\left(r_{i}, \theta_{i}\right)+\vartheta_{l}\left(\theta_{i}, t\right)+\varepsilon_{i t}
$$

where the dependent variable $\ln P_{i t}$ is the natural logarithm of transaction price of house $i$ in calendar year $t . \widetilde{D}\left(r_{i}, \tau_{i}\right)$ is the impact of religious heritage site reuse on the house price, where $r_{i}$ measures the distance in kilometers of house $i$ from the religious heritage site and $\tau_{i}$ denotes the time difference between the transaction date of house $i$ and the starting year of the reusing project. The non-parametric function $\omega_{l}\left(r_{i}, \theta_{i}\right)$ charaterizes the location fixed effects in area $l$ where house $i$ is located. The distinctive local house price trend in area $l$ is captured by $\vartheta_{l}\left(\theta_{i}, t\right)$ which could vary with $\theta$. $\varepsilon_{i t}$ is the error term.

Given that the national restoration fund provides financial support mainly based on the cultural and historical value embedded in the religious heritage sites, the choice of the neighborhoods where the adptive reuse of these sites will take place is plausibly exogenous with respect to local house price development. Hence, we can reasonably assume that the part of local house price trend unexplained by location fixed effect as well as the time fixed effect is independent of the treatment, i.e.:

$$
E\left(\varepsilon_{i t} \mid \widetilde{D}\left(r_{i}, \tau_{i}\right), w_{l}\left(r_{i}, \theta_{i}\right), \vartheta\left(\theta_{i}, t\right)\right)=0
$$

By examing house price changes close to the religious heritage site versus those slightly further away and then using difference-in-differences to eliminate fixed effects, we can recover a consistent estimate of the non-parametric gradient of $\widetilde{D}\left(r_{i}, \tau_{i}\right)$. In addition, given the fact that the treatment effect decays with distance which eventually falls to zero up to a distance of $2 \mathrm{~km}$ away from the religious heritage site, we can obtain the overall level treatment effect by integrating the estimate of non-parametric gradient.

In Eq. (2), there are three separable non-parametric functions, it is challenging to work out the estimation by standard estimation methods. To obtain the consistent estimation of the gradient of $\widetilde{D}\left(r_{i}, \tau_{i}\right)$, we follow the procedure developed by Charnigo et al. (2011) and Charnigo and Srinivasan (2015) to directly estimate the derivative of $\widetilde{D}\left(r_{i}, \tau_{i}\right)$ by differencing out additively seperable non-parametric parts. Specifically, we start with calculating the derivative of the natural logarithm of house price at each housing transaction point $\left(r_{e}, \theta_{e}, t_{e}\right)$ with respect to the distance $r$ from the religious heritage site. At the housing transaction data point $\left(r_{e}, \theta_{e}, t_{e}\right)$, we first set a boundary $U_{r, e}$ where housing transaction data points share similar $\theta$ and $t$ but differ in $r$ values:

$$
U_{r, e}:=\left\{p \in\{1,2, \ldots, n\}: \frac{\left(t_{p}-t_{e}\right)^{2}}{\left(r_{p}-r_{e}\right)^{2}}<\vartheta_{n}^{t}, \frac{\left(\theta_{p}-\theta_{e}\right)^{2}}{\left(r_{p}-r_{e}\right)^{2}}<\vartheta_{n}^{\theta}\right\}
$$


Where $e$ indexes all housing transaction points where the empirical derivative is evaluated, and $\vartheta_{n}^{t}$ and $\vartheta_{n}^{\theta}$ are the tuning parameters. Essentially, the set $U_{r, e}$ determines the eligible housing transaction points to be used for the calculation of the derivative.

Then, we obtain pairs of houses $a(k, e, r)$ and $b(k, e, r)$ by:

$$
\begin{gathered}
\left\{\begin{array}{c}
a(1, e, r)=\arg \min _{\left\{d \in U_{r, e}: r_{d}>r_{e}+\Delta r\right\}} r_{d} \\
b(1, e, r)=\arg \max _{\left\{d \in U_{r,:}: r_{d}<r_{e}-\Delta r\right\}} r_{d}
\end{array}\right. \\
\left\{\begin{array}{l}
a(k, e, r)=\arg \min _{\left\{d \in U_{r, e}: r_{d}>r_{a(k-1, e, r)}\right\}} r_{d} \\
b(k, e, r)=\arg \max _{\left\{d \in U_{r,:}: r_{d}<r_{a(k-1, e, r)}\right\}} r_{d}
\end{array}\right.
\end{gathered}
$$

Where $k$ is ranging from 1 to $k_{n}$. Houses indexed by $a(1, e, r), a(2, e, r), \ldots, a\left(k_{n}, e, r\right)$ are located further away from the religious heritage site than $r_{e}$ and are ordered by distance from $r_{e}$. In contrast, houses indexed by $b(1, e, r), b(2, e, r), \ldots, b\left(k_{n}, e, r\right)$ are located closer to the religious heritage site than $r_{e}$ and are ordered by proximity to $r_{e}$. It is worth noting that, to guarantee non-interference of the post-treatment data on pretreatment estimates, only pre-treatment data is used in calculating pre-treatment derivatives and only post-treatment data is applied to construct the post-treatment derivatives. Fig. 2 provides an example of using paired housing transactions to evaluate the empirical derivative at the housing transaction data point $e$ with respect to distance to the site of adaptive reuse project.

The calculation of the empirical derivative can be expressed by:

$$
\widetilde{P}_{e, l}=\sum_{k=1}^{k_{n}} \omega_{k} \frac{\ln p_{a(k, e, r)}-\ln p_{b(k, e, r)}}{r_{a(k, e, r)}-r_{b(k, e, r)}}
$$

$$
\omega_{k}=\frac{k}{k_{n}\left(k_{n}+1\right) / 2}
$$

Where $\widetilde{P}_{e, l}$ denotes the empirical derivative at housing transaction data point $\left(r_{e}, \theta_{e}, t_{e}\right)$ within area $l$ with $2-\mathrm{km}$ radius surrounding the religious heritage site. $\omega_{k}$ is the weight attached to the $k$ th pair of houses' difference in prices divided by difference in distance to the religious heritage site. $\widetilde{P}_{e, l}$ is thus the weighted average of $k_{n}$ pairs of houses' ratio between price difference and distance difference. Once we have calculated the empirical derivative with respect to the distance from the religious heritage site at each house transaction data point, the Nadaraya-Watson (NW) kernel estimator is applied to smooth these house price derivatives. The NW kernel estimate at $(r, t)$ is defined as: 


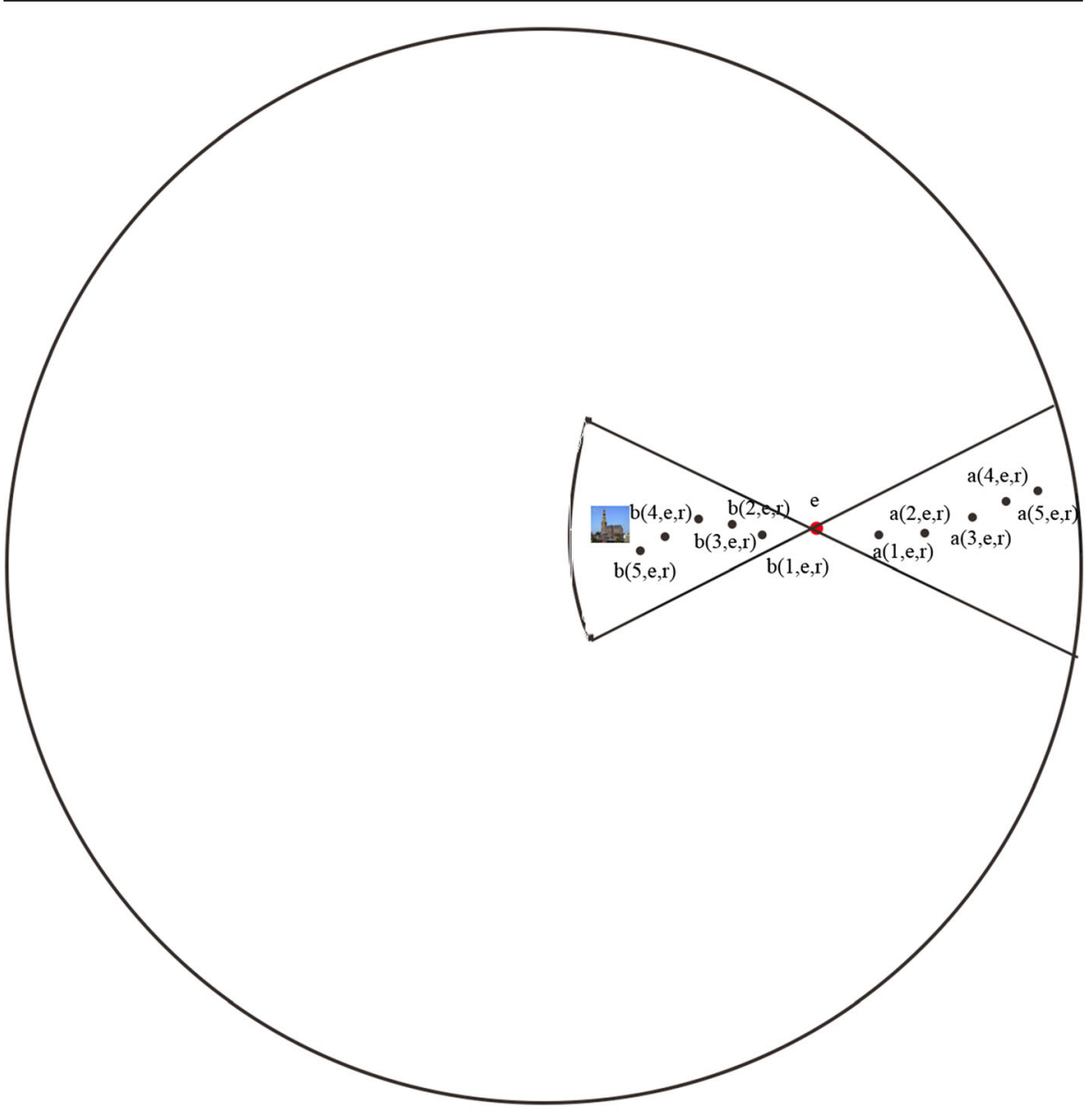

Fig. 2 Example of Pairs of Houses Used in Empirical Derivatives

$$
\begin{gathered}
M_{l}(r, t)=\frac{n^{-1} \sum_{e=1}^{n} K_{H_{n}}\left((r, t)-\left(r_{e}, t_{e}\right)\right) \widetilde{P}_{e, l}}{n^{-1} \sum_{e=1}^{n} K_{H_{n}}\left((r, t)-\left(r_{e}, t_{e}\right)\right)} \\
K_{H_{n}}\left((r, t)-\left(r_{e}, t_{e}\right)\right)=\frac{1}{h_{r, n} h_{t, n}} K\left(\frac{r-r_{e}}{h_{r, n}}, \frac{t-t_{e}}{h_{t, n}}\right)
\end{gathered}
$$

where $K(\cdot, \cdot)$ is the two-dimensional Epichanokov kernel, and $h_{r, n}$ and $h_{t, n}$ denote the corresponding bandwidth. ${ }^{2}$

\footnotetext{
${ }^{2}$ The Epichanokov kernel function is defined as $\mathrm{K}(\mathrm{u})=0.75\left(1-u^{2}\right) I(|u| \leq 1)$.

${ }^{3}$ For further details of the non-parametric difference-in-differences model estimation, we refer to Diamond and McQuade (2019).
} 
Further suppose $\Delta r \rightarrow 0, \vartheta_{n} \rightarrow 0, k_{n} \rightarrow \infty, n \rightarrow \infty, h_{n} \rightarrow 0, n h_{n} \rightarrow \infty, k_{n} / n \vartheta_{n}^{2} \rightarrow 0, \Delta r^{2} k_{n} \rightarrow \infty$, we can get the consistent gradient estimate of $\frac{\partial \widetilde{D}(r, \tau)}{\partial r}$ for each religious heritage site individually:

$$
\frac{\partial \tilde{D}(r, \tau)}{\partial r}=\hat{M}_{l}\left(r, T_{l}+\tau\right)-\hat{M}_{l}\left(r, T_{l}-1\right)
$$

where $T_{l}$ denotes the treatment year of the religious heritage site that is covered by area $l$. Then we integrate the gradient estimates to get the non-parametric level estimate of treatment effect $\widetilde{D}(r, \tau)$ as follows:

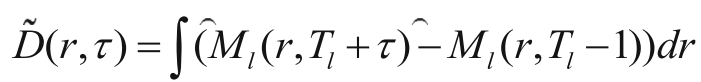

At last, we average all estimates of individual treatment effect in Eq. (12) across 42 religious heritage sites to get the average treatment effect of the religous heritage reuse. In our empirical analysis, we follow Diamond and McQuade (2019) by setting the number of house pairs used in the calculation of empirical derivative to be 5 , i.e. $k_{n}=5$, $\vartheta_{n}^{t}=1.6$ and $\vartheta_{n}^{\theta}=0.4, \Delta r=0.01$ in kilometers, $h_{r, n}=0.3$ (the bandwidth for smoothing in kilometers), and $h_{t, n}=5$ (the bandwidth for smoothing in years). ${ }^{3}$

\section{Data}

In the empirical analysis, three datasets are assembled. Firstly, we collect data on religious heritage reuse projects in the Netherlands from the website of the Restoration Fund (https://www.herbestemming.nu/). The Restoration Fund was established as a non-profit organization in 1985 , being committed to the maintenance, restoration and reuse of Dutch monuments by providing financing and knowledge support. For each project, we can identify the exact location, the starting year and completion year of transformation, the original and reused function, project size, monument status, etc. Table 1 contains the descriptive statistics for the religious heritage dataset. There are 42 religious heritage sites which are successfully reused in the Netherlands from 1995 to 2017 with the support provided by the Restoration Fund. 64\% of these reused religious heritage sites are national monuments. On average, the size of religious heritage reuse project is 4659 square meters, and masks substantial heterogeneity. Fig. 3 shows the spatial distribution of 42 religious heritage sites that we use in our analysis.

Secondly, we obtain housing transaction data from the Dutch association of brokers (NVM). NVM is the largest national association of real estate brokers and real estate experts in the Netherlands with approximately 4000 members nationwide. Almost $75 \%$ of Dutch houses are sold by the NVM members. This dataset involves housing transactions from 1995 to 2017 with more than 2 million observations, which contains information on the exact location, the transaction date, selling price as well as a set of

\footnotetext{
${ }^{4}$ To eliminate the potential bias caused by outliers, we exclude observations with transaction prices that are above $€ 1.5$ million or below $€ 10,000$. Furthermore, we also exclude observations that have more than 10 rooms.
} 
Table 1 Descriptive Statistics: Religious Heritage Sites

\begin{tabular}{llr}
\hline & Mean & S.D. \\
\hline Starting year & 2005 & 4.26 \\
Completion year & 2008 & 3.73 \\
Project duration (year) & 3 & 2.87 \\
National monument (yes =1) & 0.64 & 0.48 \\
Project size (square meters) & 4659 & 5100 \\
Number of observations & 42 & \\
\hline
\end{tabular}

structural attributes of each sold house, such as the house type, building year, floor size, number of rooms, lift, parking, balcony, garden, etc. For each house, we use the latitude and longitude information to calculate the distance to the nearest religious heritage site.

To control for time-varying local characteristics, we supplement the housing transaction data with data on neighborhood characteristics. This third dataset is provided by Statistics Netherlands (CBS), which includes information about population density, average household size, the share of immigrants and age distribution over the population. We use GIS to spatially merge this dataset with the housing transaction dataset.

Table 2 shows descriptive statistics for the housing transaction dataset and neighborhood characteristics. ${ }^{4}$ In our sample, the average housing transaction price from 1995 to 2017 is $€ 221,777$ and the average size and number of rooms is $102 \mathrm{~m}^{2}$ and 3.87 respectively. About half of sold houses were constructed before 1945 . We identify 1623 unique neighborhoods in our sample. On average, population density of the neighborhood is 9536 persons per $\mathrm{km}^{2}$. The average household size is 1.99 , and $23.34 \%$ of residents are immigrants. The majority of the residents ages below 45 .

\section{Empirical Results}

\section{Parametric Difference-in-Differences Estimates}

We begin with examining the average treatment effect deduced from the parametric difference-in-differences specification. Table 3 reports the empirical results. Year fixed effects and neighborhood fixed effects are included to capture the influence of aggregate market price trends and all time-invariant neighborhood attributes. Column (1) and (2) show the empirical results produced using the full sample that includes all the 42 religious heritage reuse projects and they differ in terms of the inclusion of control variables. In column (1), with the exclusion of housing and neighborhood characteristics, properties that are close to the reusing religious heritage sites enjoy a premium of $3.99 \%$ relative to their counterparts in the control area. After including all control variables, the estimated treatment effect drops to $2.17 \%$ and remains statistically significant. Overall, it suggests that religious heritage reuse exerts significantly positive spillover in local housing market. These results are consistent with the findings in the previous literature, for example, Schwartz et al. (2006), Van Duijn et al. (2016), Lee 


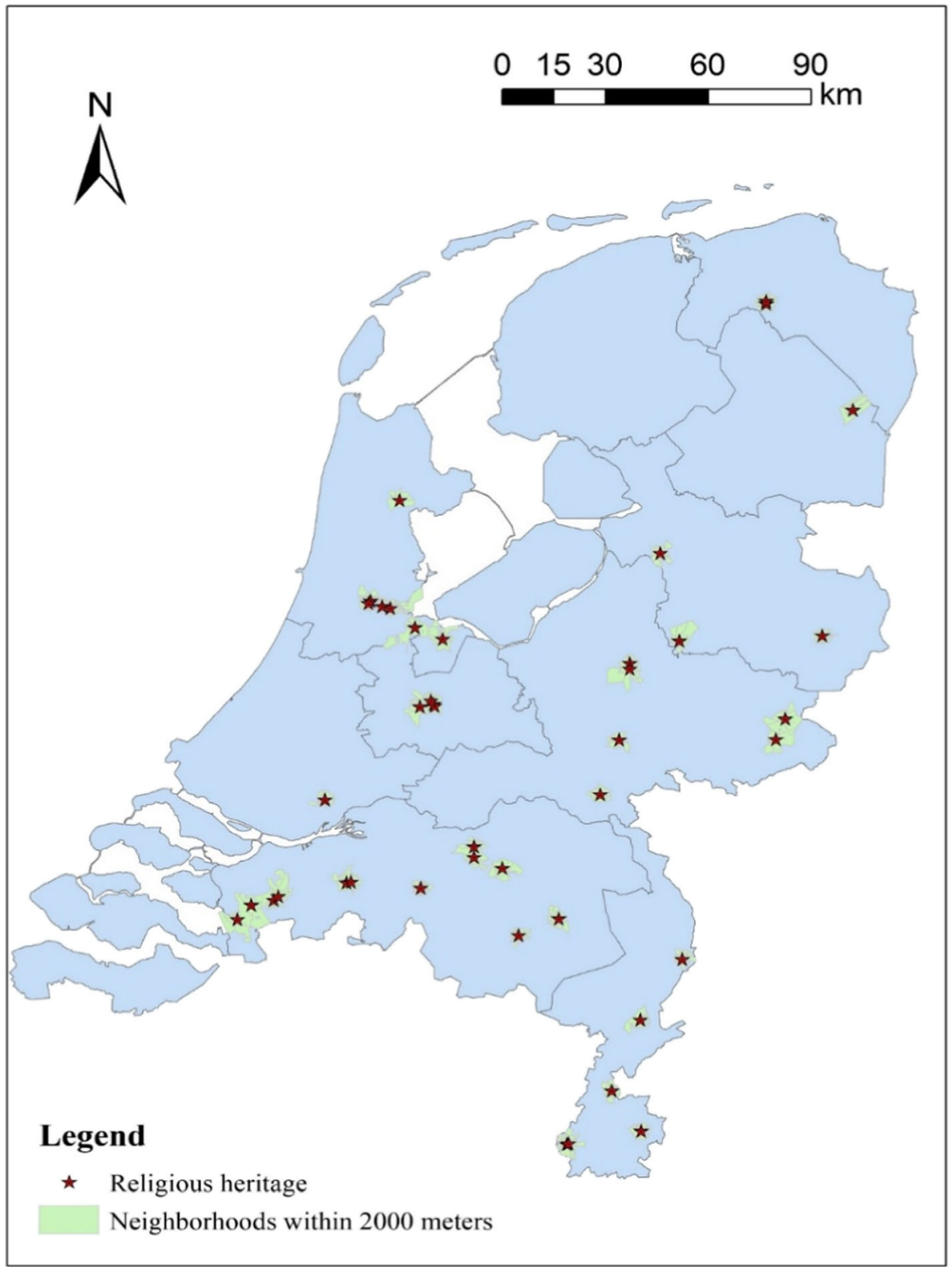

Fig. 3 The Location of 42 Religious Heritage Sites

et al. (2017) that documents positive externality imposed by urban revitalization projects on local house prices.

Among the 42 religious heritage reuse projects, heterogeneity exists in terms of project size. It is likely that large reuse projects get more financial investment and public attention, which would contribute to greater external effects on surrounding house prices than those of smaller projects. To test this, we select those religious 
Table 2 Descriptive Statistics of Full Sample

\begin{tabular}{|c|c|c|}
\hline & Mean & S.D. \\
\hline \multicolumn{3}{|l|}{ Panel A: Housing characteristics } \\
\hline Transaction price $(€)$ & $221,776.97$ & $144,487.2$ \\
\hline Lift (yes $=1$ ) & 0.11 & 0.31 \\
\hline Size $\left(m^{2}\right)$ & 102.07 & 42.7 \\
\hline Number of rooms & 3.87 & 1.48 \\
\hline Parking (yes = 1) & 0.2 & 0.4 \\
\hline Garden $($ yes $=1)$ & 0.47 & 0.5 \\
\hline Balcony (yes = 1) & 0.4 & 0.49 \\
\hline Roofterrace (yes = 1) & 0.1 & 0.3 \\
\hline Building year $<1945$ (yes = 1) & 0.5 & 0.5 \\
\hline Building year 1945-1959 (yes = 1) & 0.1 & 0.3 \\
\hline Building year 1960-1970 (yes = 1) & 0.13 & 0.34 \\
\hline Building year 1971-1980 (yes = 1) & 0.06 & 0.25 \\
\hline Building year 1981-1990 (yes = 1) & 0.06 & 0.25 \\
\hline Building year 1991-2000 (yes =1) & 0.08 & 0.28 \\
\hline Building year >2000 $($ yes $=1)$ & 0.06 & 0.23 \\
\hline Housing type-Apartment (yes $=1$ ) & 0.57 & 0.5 \\
\hline Housing type-Semi-detached house (yes $=1$ ) & 0.32 & 0.47 \\
\hline Housing type-Corner house (yes $=1$ ) & 0.08 & 0.27 \\
\hline Housing type-Detached house $($ yes $=1$ ) & 0.03 & 0.18 \\
\hline Observations & 342,439 & \\
\hline \multicolumn{3}{|l|}{ Panel B: Neighborhood characteristics } \\
\hline Population density (per km²) & 9536.01 & 6362.37 \\
\hline Average household size & 1.99 & 0.49 \\
\hline Proportion of immigrants (\%) & 23.34 & 15.79 \\
\hline Population aged 0-14 (\%) & 13.55 & 4.98 \\
\hline Population aged $15-24(\%)$ & 15.02 & 6.92 \\
\hline Population aged 25-44 (\%) & 35.87 & 8.86 \\
\hline Population aged 45-64 (\%) & 22.44 & 5.26 \\
\hline Population aged 65 and over (\%) & 13.12 & 7.38 \\
\hline Number of neighbourhoods & 1623 & \\
\hline
\end{tabular}

heritage reuse projects with size over 5000 square meters as a subsample. Column (3) and (4) report the average treatment effect of large scale religious heritage reuse projects. The coefficient presented in Column (3) indicates that religious heritage reuse projects with size over 5000 square meters lead to an increase in local house prices by $7.15 \%$, which is larger than the average treatment effect estimated using all religious heritage reuse projects as shown in column (1). Similar finding is reported after controlling for housing and neighborhood characteristics in Column (4). The results 
Table 3 Parametric Difference-in-Differences Estimates

\begin{tabular}{|c|c|c|c|c|c|c|}
\hline \multirow[b]{2}{*}{ DV: $\ln p$} & \multicolumn{2}{|c|}{ Full sample } & \multicolumn{2}{|c|}{ Project size $\geq 5000 \mathrm{~m}^{2}$} & \multicolumn{2}{|c|}{ National monuments } \\
\hline & (1) & (2) & (3) & (4) & (5) & (6) \\
\hline \multirow[t]{2}{*}{ treat $\times$ post } & $0.0399^{* * * *}$ & $0.0217^{* * * *}$ & $0.0715^{* * *}$ & $0.0338^{* * *}$ & $0.0459^{* * *}$ & $0.0228^{* * *}$ \\
\hline & $(0.002)$ & $(0.001)$ & $(0.007)$ & $(0.003)$ & $(0.004)$ & $(0.002)$ \\
\hline Housing characteristics & no & yes & no & yes & no & yes \\
\hline Neighborhood characteristics & no & yes & no & yes & no & yes \\
\hline Year fixed effects & yes & yes & yes & yes & yes & yes \\
\hline Neighborhood fixed effects & yes & yes & yes & yes & yes & yes \\
\hline Observations & 342,439 & 342,439 & 64,337 & 64,337 & 159,980 & 159,980 \\
\hline Adjusted $\mathrm{R}^{2}$ & 0.585 & 0.866 & 0.544 & 0.872 & 0.588 & 0.866 \\
\hline
\end{tabular}

Note: ${ }^{* * *},{ }^{* *},{ }^{*}$ denotes the significance of coefficients at $1 \%, 5 \%$ and $10 \%$ respectively. The dependent variable is the natural log of house transaction price. Robust standard errors are reported in parentheses

imply that large scale religious heritage reuse projects bring more positive impact on local house prices than that of reuse projects with relatively smaller size.

Next to the scale difference among reuse projects, these projects also vary in terms of their designated monumental status. In the Netherlands, historical buildings, including religious heritage sites, are listed with various monumental status, such as national monument, provincial monument, municipal monument or no monumental status at all, based on their cultural and historical values. It is perceivable that religious heritage sites designated with national monument status may bring reputation effects such that they

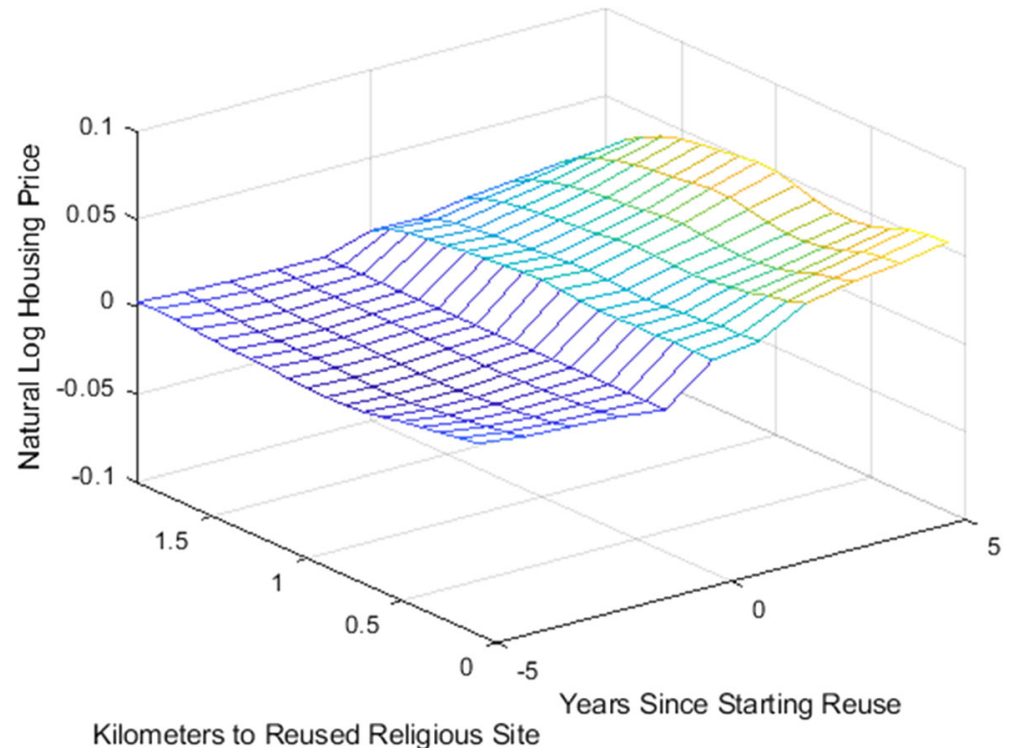

Fig. 4 Average Price Impact of 42 Religious Heritage Reuse Projects 


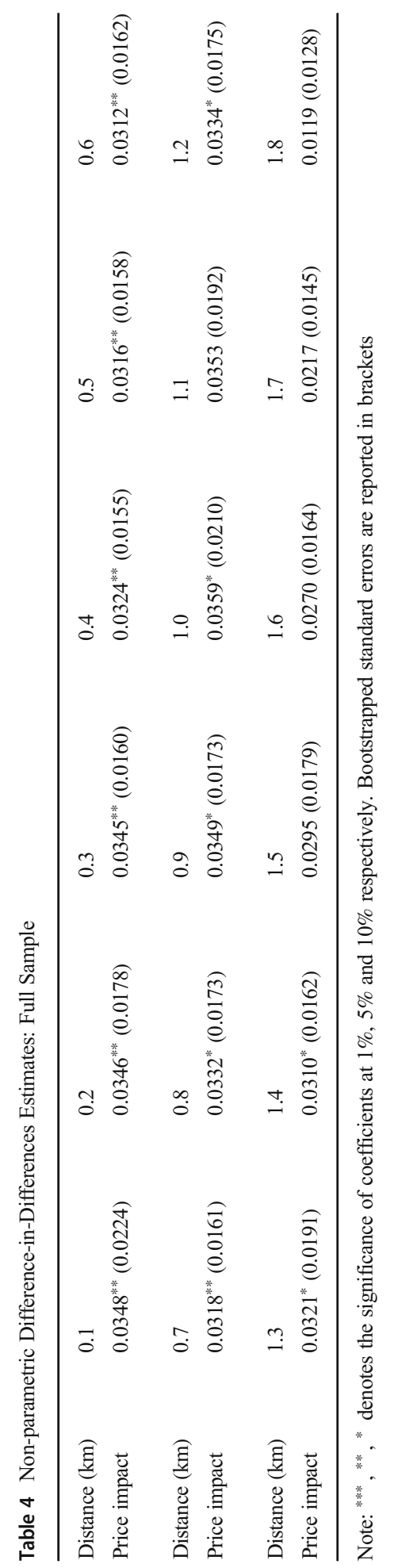


are more attractive to local residents, and there is a higher chance for them to be qualified for financial support aiming at maintenance and renovation than those without such a distinguished status (Koster and Rouwendal 2017). Therefore, it seems plausible that such reputation effects would be reflected in the estimated treatment effect so that projects of reusing religious heritage sites with national monumental status would impose greater positive externality on local housing market than that of other projects. To check if this is the case, we re-estimate the model using only those sites listed as national monuments and results are displayed in Column (5) and (6). Comparing the coefficient estimates of the treatment variable shown in Column (5) and (6) with their respective counterparts listed in Column (1) and (2) that are estimated using the full sample, it appears that the average treatment effect is indeed larger for projects of reusing religious heritage listed as national monuments.

\section{Non-parametric Difference-in-Differences Estimates}

The parametric difference-in-differences specification offers a rather straightforward way to measure the average treatment effect of reusing religious heritage sites, however, it fails to make distinction of treatment effect variation along both the spatial and temporal dimensions. In contrast, with the non-parametric difference-in-differences specification, we are able to recover the gradient of treatment effect of reusing religious heritage sites across space and time. Fig. 4 is the wireframe mesh plot which illustrates the average treatment effect of 42 religious heritage reuse projects over space and time. The mesh grid color is determined by the value of house price in natural log, and proportional to surface height. As shown in Fig. 4, the house price surface before the commencement of religious heritage reuse projects is quite flat, which validates that

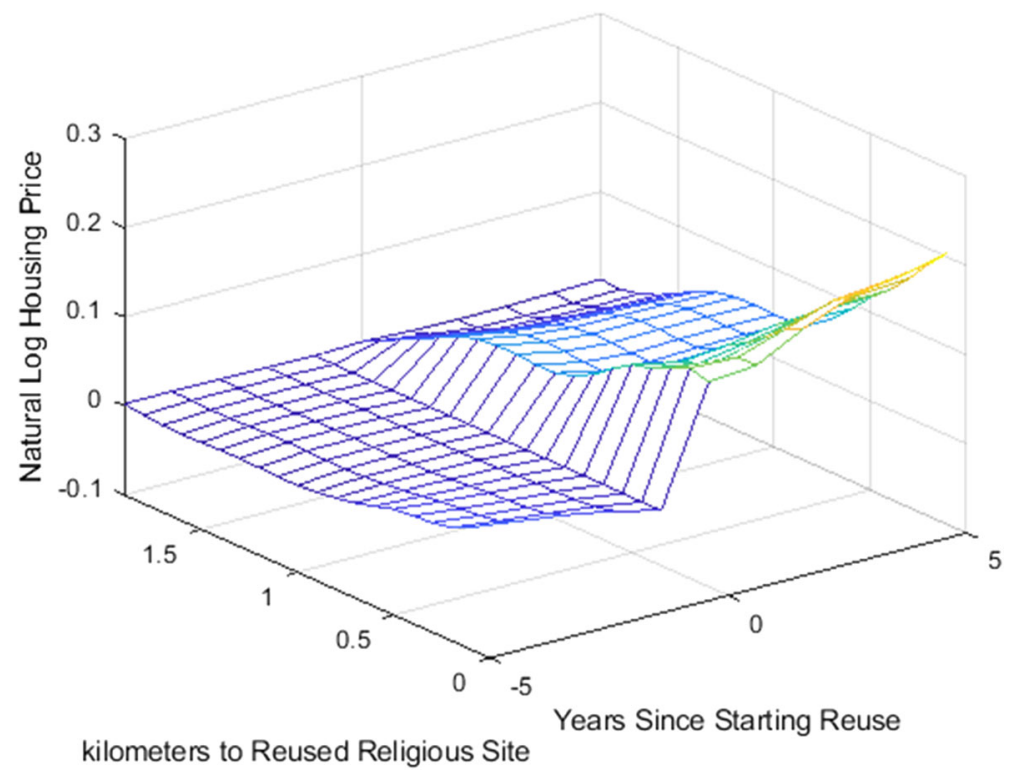

Fig. 5 Price Impact of Religious Heritage Reuse with Project Size larger than 5000 Square Meters 


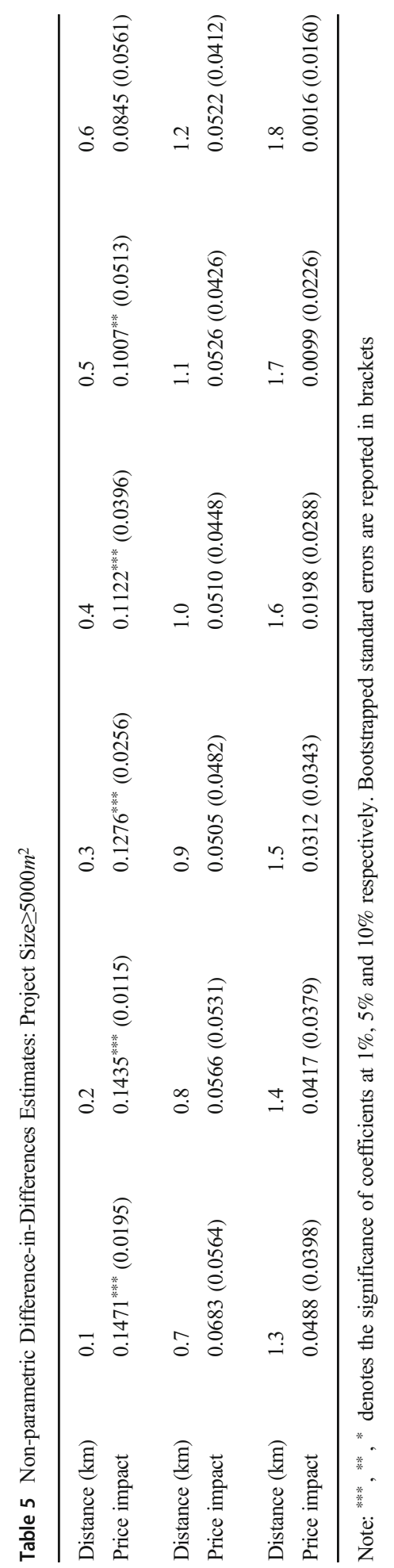


house prices close to the religious heritage site and house prices slightly further away from the site share similar trends before the treatment. After the religious heritage starts the reuse process, the house price surface jumps up steeply, indicating that religious heritage reuse indeed has positive impact on local house prices. 5 years after the start of the projects, the religious heritage reuse triggers house price appreciation within its close proximity, i.e. $0.1 \mathrm{~km}$, by approximately $5.2 \%$.

To illustrate the treatment effect of religious heritage reuse numerically, Table 4 summarizes those point estimates shown in Fig. 4 and the price impacts reported in Table 4 are the average treatment effect estimated as the price difference between the post-treatment years, i.e. 0 to 5 years, and pre-treatment years, i.e. -5 to -1 years, at each $0.1-\mathrm{km}$ distance to the religious heritage site. Between 0.1 and $0.7 \mathrm{~km}$ distance to the religious heritage site, house price appreciation is $3.1 \sim 3.5 \%$ after the start of the reuse project, and is statistically significant at the $5 \%$ level. Similar degree of price appreciation is observed for houses located between 0.8 and $1.4 \mathrm{~km}$ distance to the religious heritage site, but is only significant at the $10 \%$ level. For houses that are located further than $1.4 \mathrm{~km}$ to the religious heritage site, the treatment effect becomes smaller and statistically insignificant.

Next, we keep those religious heritage reuse projects with size more than 5000 square meters to investigate whether the treatment effect is heterogeneous based on the project size. Fig. 5 presents the mesh plot of the price impacts of large-scale religious heritage reuse projects. Similar to the non-parametric results using the full sample, the house price surface remains low and flat up to the start of the religious heritage reuse projects. When reuse projects are initiated, the house price surface is first elevated sharply then flattens off gradually until year 5 . For houses located $0.1 \mathrm{~km}$ away from the religious heritage site, the price appreciation is about $20 \%$ after 5 years since the start of reuse project.

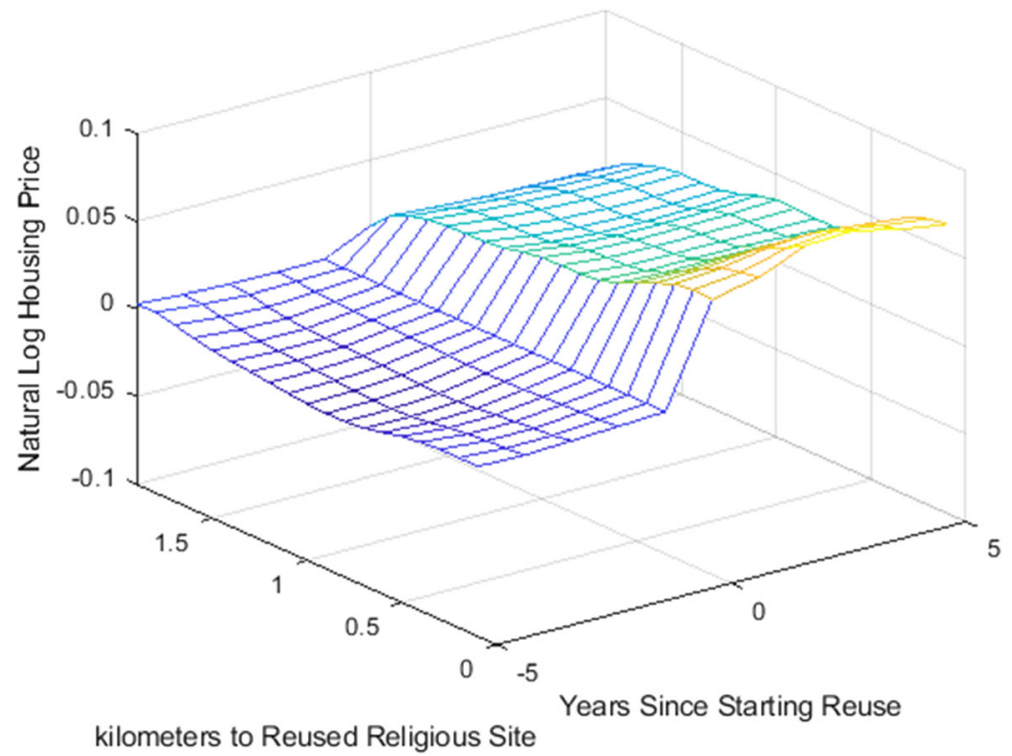

Fig. 6 Price Impact of Reusing Religious Heritage Designated as National Monument 


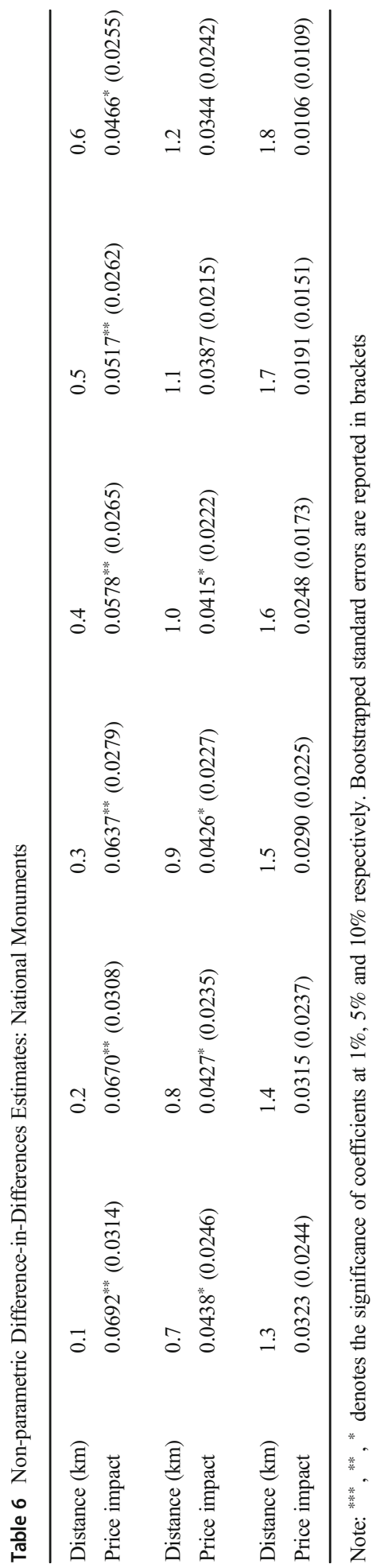


Table 5 reports the average treatment effect of large-scale projects across space. Overall, the house price appreciation triggered by these large religious heritage reuse projects exhibits spatial decay which is more pronounced than that reported in Table 4, and the treatment effect of these projects are much greater in comparison with the nonparametric results using the full sample. Specifically, large projects contribute to house price increase by $14.7 \%$ at the $0.1-\mathrm{km}$ distance, which is statistically significant at the $1 \%$ level. From $0.2-\mathrm{km}$ to $0.5-\mathrm{km}$ distance to the religious heritage site, the extent of house price appreciation drops gradually from $14 \%$ to $10 \%$ and remains statistically significant at least at the $5 \%$ level. Beyond $0.6 \mathrm{~km}$, the average treatment effect keeps decreasing over space but becomes statistically insignificant.

Further, we restrict the non-parametric estimation using religious heritage sites designated with national monument status. Fig. 6 demonstrates the treatment effect of these religious heritage reuse projects over space and time. The house price surface exhibits similar pattern to those shown in Figs. 4 and 5. At $0.1-\mathrm{km}$ distance to the religious heritage site listed as national monument, local house price appreciation is approximately $7 \%$ after 5 years since the initiation of reuse project. Table 6 reports the spatial distribution of the average treatment effect of reusing the religious heritage sites with national monument status. Overall, the house price impact decreases with the distance to the religious heritage site. Between $0.1-\mathrm{km}$ and $0.5-\mathrm{km}$ distance to the religious heritage site, reusing religious heritage listed as national monument pushes up local house prices by $5 \sim 7 \%$, and the treatment effect is statistically significant at the $5 \%$ level. In terms of the magnitude, the price impacts are larger than those reported in Table 4. From $0.6-\mathrm{km}$ to $1-\mathrm{km}$ distance to the religious heritage sites, the average treatment effect drops gradually from $4.7 \%$ to $4.2 \%$ which is significant at the $10 \%$ level. These religious heritage reuse projects do not seem to have significant impact on house prices further than $1.1 \mathrm{~km}$ distance to the sites.

\section{Conclusion}

In this paper, we examine the external effect of reusing religious heritage on local house prices. We begin with employing the standard parametric difference-in-differences approach to estimate the average treatment effect of religious heritage reuse by comparing house prices within an inner ring, i.e. treatment area, with house prices in the outer ring, i.e. control area, before and after the treatment. We then resort to a novel non-parametric difference-in-differences method to estimate the spatial and temporal variation of the treatment effect of reusing religious heritage sites.

Using 42 completed reuse projects that spread across the Netherlands and span the period from 1995 to 2017, findings from both the parametric and non-parametric estimation reveal the presence of positive external effect of reusing religious heritage sites on surrounding house prices. We further show that the project size and monument status are the driving factors in determining the magnitude of observed positive externality associated with reusing the religious heritage. Overall, these results indicate that the adaptive reuse contributes to not only the historical and cultural preservation in place but also the welfare of local communities in terms of housing price capitalization.

This study could be a useful reference towards better understanding of the welfare implications of historic preservation and urban revitalization policies. To a certain 
extent, our findings provide empirical evidence in support of the effectiveness of urban policies concerning the adaptive reuse of abandoned religious heritage sites. From policy makers' perspective, it would, however, be interesting to incorporate the costs involved in the reuse projects to determine the net welfare effect relating to adaptive reuse. In addition, whether the findings of this study can be generalized in reuse projects other than religious heritage is not yet known. Therefore, we leave these queries for future research.

Acknowledgments We would like to thank Mark van Duijn, Michiel Daams, Jie Chen, Jouke van Dijk, Anping Chen, the anonymous referee and the editor of this journal for their constructive comments and suggestions. We are also thankful to Dutch Association of Real Estate Brokers (NVM) and Statistics Netherlands (CBS) for providing data, and to Rebecca Diamond and Tim McQuade for sharing the Matlab codes for this research. Financial support from China Scholarship Council is gratefully acknowledged.

Open Access This article is licensed under a Creative Commons Attribution 4.0 International License, which permits use, sharing, adaptation, distribution and reproduction in any medium or format, as long as you give appropriate credit to the original author(s) and the source, provide a link to the Creative Commons licence, and indicate if changes were made. The images or other third party material in this article are included in the article's Creative Commons licence, unless indicated otherwise in a credit line to the material. If material is not included in the article's Creative Commons licence and your intended use is not permitted by statutory regulation or exceeds the permitted use, you will need to obtain permission directly from the copyright holder. To view a copy of this licence, visit http://creativecommons.org/licenses/by/4.0/.

\section{References}

Aarland, K., Osland, L., \& Gjestland, A. (2017). Do area-based intervention programs affect house prices? A quasi-experimental approach. Journal of Housing Economics, 37, 67-83.

Ahlfeldt, G. M., \& Maennig, W. (2010). Substitutability and complementarity of urban amenities: External effects of built heritage in Berlin. Real Estate Economics, 38(2), 285-323.

Asabere, P. K., Huffman, F. E., \& Mehdian, S. (1994). The adverse impacts of local historic designation: The case of small apartment buildings in Philadelphia. The Journal of Real Estate Finance \& Economics, 8(3), 225-234.

Charnigo, R., \& Srinivasan, C. (2015). A multivariate generalized C p and surface estimation. Biostatistics, 16(2), 311-325.

Charnigo, R., Hall, B., \& Srinivasan, C. (2011). A generalized C p criterion for derivative estimation. Technometrics, 53(3), 238-253.

Coulson, N. E., \& Leichenko, R. M. (2001). The internal and external impact of historical designation on property values. The Journal of Real Estate Finance \& Economics, 23(1), 113-124.

De Sousa, C. A., Wu, C., \& Westphal, L. M. (2009). Assessing the effect of publicly assisted brownfield redevelopment on surrounding property values. Economic Development Quarterly, 23(2), 95-110.

Diamond, R., \& McQuade, T. (2019). Who wants affordable housing in their backyard? An equilibrium analysis of low-income property development. Journal of Political Economy, 127(3), 1063-1117.

Diamond, D, B., \& Tolley, G, S. (Eds.). (2013). The economics of urban amenities. Elsevier.

Dröes, M. I., \& Koster, H. R. (2016). Renewable energy and negative externalities: The effect of wind turbines on house prices. Journal of Urban Economics, 96, 121-141.

Halman, L., \& Draulans, V. (2006). How secular is Europe? The British Journal of Sociology, 57(2), 263-288.

Heath, T., Oc, T., \& Tiesdell, S. (2013). Revitalising historic urban quarters. New York: Routledge.

Heintzelman, M. D., \& Altieri, J. A. (2013). Historic preservation: Preserving value? The Journal of Real Estate Finance \& Economics, 46(3), 543-563.

Koster, H. R., \& Rouwendal, J. (2017). Historic amenities and housing externalities: Evidence from the Netherlands. The Economic Journal, 127(605), 396-420.

Latham, D. (2016). Creative reuse of buildings: Volume one. New York: Routledge. 
Lee, C., Liang, C., \& Chen, C. (2017). The impact of urban renewal on neighborhood housing prices in Taipei: An application of the difference-in-difference method. Journal of Housing \& the Built Environment, 32, 407-428.

Liang, C., Lee, C., \& Yong, L. (2020). Impacts of urban renewal on neighborhood housing prices: Predicting response to psychological effects. Journal of Housing \& the Built Environment, 35, 191-213.

Noonan, D. S. (2007). Finding an impact of preservation policies: Price effects of historic landmarks on attached homes in Chicago, 1990-1999. Economic Development Quarterly, 21(1), 17-33.

Noonan, D. S., \& Krupka, D. J. (2011). Making-Or picking-Winners: Evidence of internal and external price effects in historic preservation policies. Real Estate Economics, 39(2), 379-407.

Ooi, J. T., \& Le, T. T. (2013). The spillover effects of infill developments on local housing prices. Regional Science \& Urban Economics, 43(6), 850-861.

Ruiter, S., \& Van Tubergen, F. (2009). Religious attendance in cross-national perspective: A multilevel analysis of 60 countries. American Journal of Sociology, 115(3), 863-895.

Schwartz, A. E., Ellen, I. G., Voicu, I., \& Schill, M. H. (2006). The external effects of place-based subsidized housing. Regional Science \& Urban Economics, 36(6), 679-707.

Small, K. A., \& Steimetz, S. S. (2012). Spatial hedonics and the willingness to pay for residential amenities. Journal of Regional Science, 52(4), 635-647.

van Duijn, M., Rouwendal, J., \& Boersema, R. (2016). Redevelopment of industrial heritage: Insights into external effects on house prices. Regional Science \& Urban Economics, 57, 91-107.

Velthuis, K., \& Spennemann, D. H. (2007). The future of defunct religious buildings: Dutch approaches to their adaptive re-use. Cultural Trends, 16(1), 43-66.

Woo, A., \& Lee, S. (2016). Illuminating the impacts of brownfield redevelopments on neighboring housing prices: Case of Cuyahoga County, Ohio in the US. Environment \& Planning A, 48(6), 1107-1132.

Wu, W., \& Wang, J. (2017). Gentrification effects of China's urban village renewals. Urban Studies, 54(1), 214-229.

Zahirovic-Herbert, V., \& Gibler, K. M. (2014). Historic district influence on house prices and marketing duration. The Journal of Real Estate Finance \& Economics, 48(1), 112-131.

Publisher's Note Springer Nature remains neutral with regard to jurisdictional claims in published maps and institutional affiliations. 